\title{
Relative vulnerabilities of urban residential development to oil depletion: pilot case studies of a representative building typology in the Australian context
}

\author{
R. J. Brewster \\ Faculty of Society and Design, Bond University, Australia
}

\begin{abstract}
The global production of conventional oil is predicted to have peaked in the first decade of this century and then gradually declined, leading to eventual adverse consequences for direct and indirect oil related inputs to urban land development and residential construction. This paper reports the $\mathrm{PhD}$ case study investigation into adapting urban residential development to an oil-constrained future in the Australian and wider context. The research is grounded in a general theoretical framework of sustainable development theory, encompassing urban metabolism and partial life cycle analysis. The oil dependency relationship is demonstrated by material flow analysis of petroleum (oil and gas) related inputs into residential development. The relative oil depletion vulnerabilities are quantified by a pilot case study of four building types, representative of the residential typology in the reference City of Gold Coast. The cross-case comparison finds that oil-related inputs affect all building types. Embodied energy is least for a detached house, increasing for the three, six and thirty storey apartment buildings. Empirically, the medium rise six storey case is the most energy efficient higher density form and offers other advantages to reduce urban sprawl and improve urban design outcomes. The research points to a proposition that all forms of urban residential development will be affected by oil constraints.

Keywords: oil depletion, sustainable construction, embodied energy, life cycle assessment, six-storeys.
\end{abstract}




\section{Introduction}

The twentieth century has been the era of abundant supplies of petroleum and the dominance of the private motor car (automobile). The urban form of once compact cities has bloated into sprawling car dominated metropolitan regions [1]. The era of cheap oil has ended. The International Energy Agency (IEA) [2] confirms a 6\% decline rate in existing conventional oil fields. The IEA predicts a fall in output from 70 million barrels per day (mb/d) in 2006 to $30 \mathrm{mb} / \mathrm{d}$ by 2035 . The global peaking of oil production prompted a $\mathrm{PhD}$ investigation [3] of the relationship between oil constraints and urban residential development in the Australian context; and how the built environment affected by eventual oil depletion might influence future urban form. This paper presents the results of a pilot case study investigation into relative vulnerabilities of four representative building types. Space limitation precludes full details in the $\mathrm{PhD}$ to be published.

\section{Case studies of representative building typology}

The pilot case study applies to a representative residential typology of the hypothetical urban transect of the City of Gold Coast (shown in figure 1). The cases highlight differences in design and construction (as illustrated in figure 2). The methodology rests of the foundation of sustainable development, measured by urban metabolism and life cycle analysis. Partial material flow analysis (MFA) is used to investigate relative vulnerabilities to petroleum-related (oil/gas) inputs. The outcomes of this analysis form the basis for a cross-case comparison the range of buildings to assess the influence on future urban form.

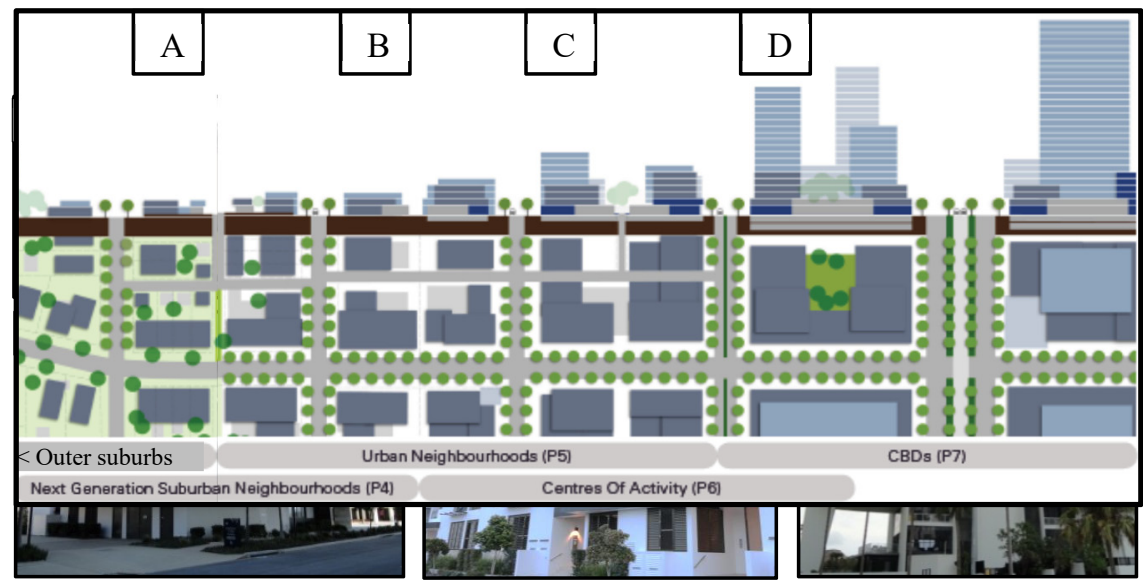

Figure 1: Conceptualised urban transect of a South East Queensland city (source: adapted from Duany et al. [4]). 

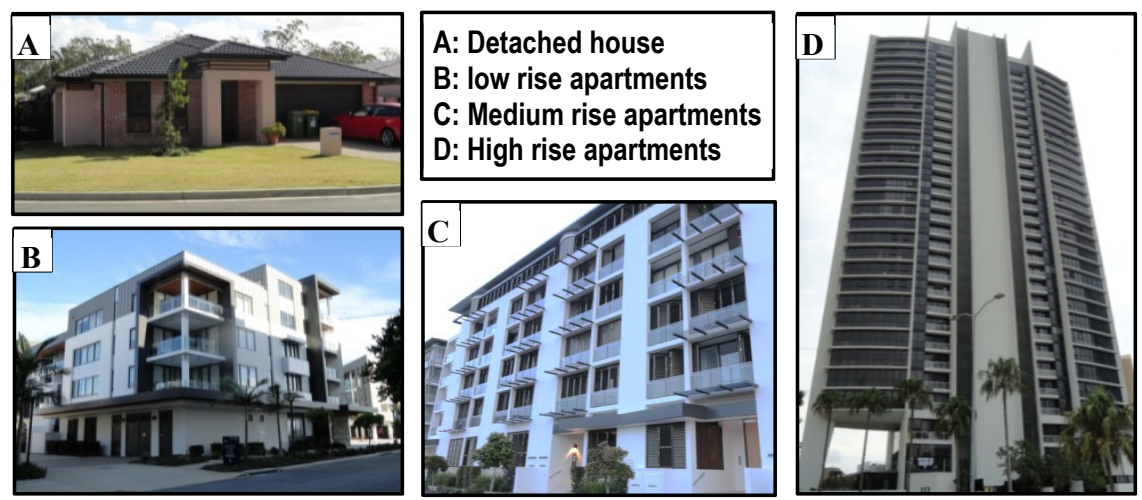

Figure 2: Case study representative residential building typology (photos by the author).

The cases in figure 2 reflect the Gold Coast City planning categories:

Case A: Detached single storey house: the dominant suburban neighbourhood.

Case B: Low rise apartment building of (modified) three storeys over parking at ground level with lifts: the urban neighbourhood.

Case C: Medium rise, elongated shape apartment building of six storeys with one parking basement and lifts: inner urban neighbourhood.

Case D: High rise apartment tower of 30 storeys with three parking basement levels and lifts: the central business district and activity centres.

Common elements of the residential buildings include:

- the land development and road construction

- the manufacturing and installation of internal dwelling components.

An archival research approach is used to analyse data sets provided by participating developers and create vulnerability indices for each case, based on embodied energy intensity per unit of gross floor area (GFA). The cases are also compared on the basis of the energy intensity per bedroom and occupancy rate for the typical dwelling units. Each case type has a similar level of internal fitout for consistency across the cases. The detached dwelling house is regarded as the base case for indexing purposes.

The main findings for the individual cases are summarised to provide sufficient information to follow the cross-case comparison in section 3.

\subsection{Pilot case study A: single level detached house}

Case A is a typical Gold Coast suburban single level house shown in figure 2. The construction is face brick veneer on timber wall frames and roof trusses, lined with plasterboard internal walls and ceiling, and concrete tiled hip roof. The footings and ground floor are a waffle pod concrete slab that minimises trenching and ground disturbance. The layout is in figure 3 and results in table 1. 


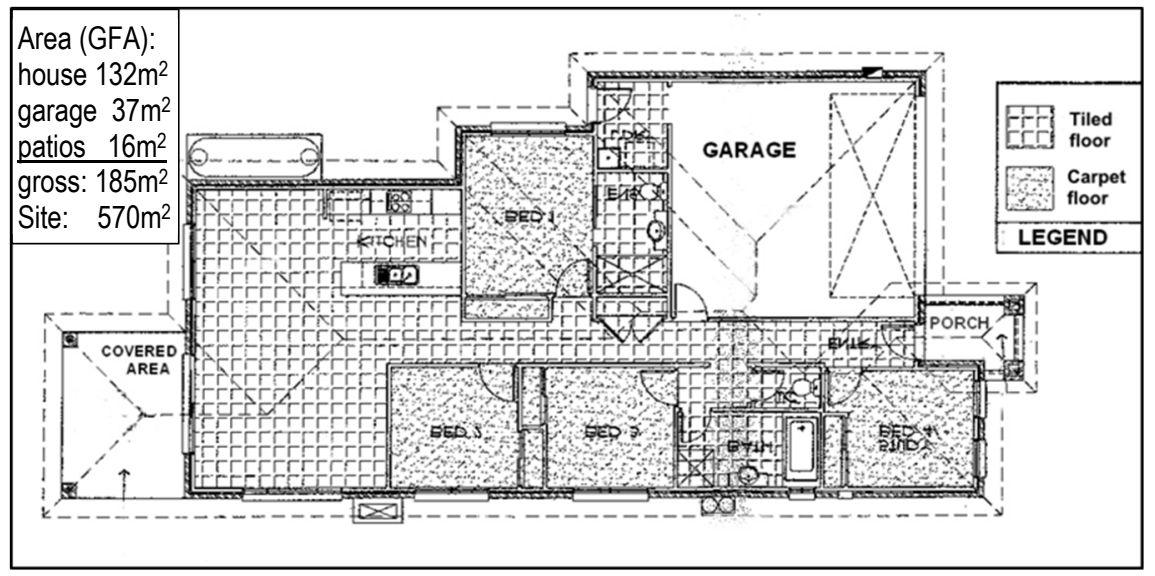

Figure 3: General layout of case study house (source: provided by case study developer with permission).

\subsubsection{Results summary of oil and gas related inputs}

A similar Melbourne study enabled additional proportional direct energy requirements (DER) amounting to $545 \mathrm{GJ}$ to be added to this case (Crawford [5]). The total estimated embodied energy for the recorded material items in table 1 (2273 GJ) plus DER (545 GJ) of the $185 \mathrm{~m}^{2}$ house is 2818 GJ. This compares with an estimated $3994 \mathrm{GJ}$ for the $308 \mathrm{~m}^{2}$ Crawford case study house.

Table 1: $\quad$ Summary of case A detached house analysis.

\section{Oil related direct input:}

Bitumen minimum

$1.6 \mathrm{~m}^{3}$

\section{Oil/gas related indirect input (some partially or not quantified):}

PVC pipes (various diameters)

Polyethylene sheet

Expanded polystyrene waffle pods

PVC cable sheathing

Sealants and paint (total area)

Melamine kitchen cabinets and robe shelving Carpet

\section{Recorded estimated embodied energy:}

Total land/road development (GJ)

Total essential infrastructure (GJ)

Total building materials (GJ)

Household appliances and equipment (GJ)

Total freight transport (20 km distance) (GJ)

Total process embodied energy approx.

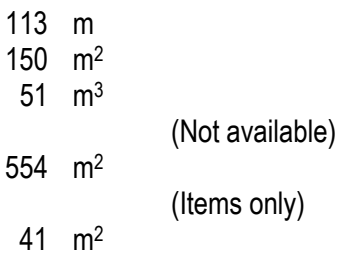

\section{Per dwelling Per m2 GFA}

\begin{tabular}{rr}
117.70 & 0.64 \\
49.90 & 0.27 \\
1930.05 & 10.43 \\
166.25 & 0.90 \\
9.52 & 0.05 \\
\hline 2273.42 & 12.29
\end{tabular}

Direct and indirect oil and gas inputs $=42 \mathrm{GJ}$ plus waffle pods $359 \mathrm{GJ}$ 


\subsubsection{Analysis of oil inputs findings}

The subtleties of oil and gas inputs are easy to lose in the inventory, especially in relation to upstream materials processing. The analysis is therefore regarded as a conservative estimate of the material and energy inputs into this building type. The total direct and indirect oil/gas inputs amount to $401 \mathrm{GJ}$, which represent $21 \%$ of the 1930 GJ structural energy. The direct energy consumption for construction of the house is of the order of $350 \mathrm{kWh}$ of electricity at peak rates when taken from mains power, according to the case construction manager. This is a small amount - only about half of a typical three months of operating power.

As in all the other cases of the study, transport of materials and labour is the largest direct oil-related input, based on current transport fuels. Hence the deceptively small recorded transport embodied energy (9.52 GJ) is not the whole story in examining the possible oil related impacts in an oil constrained scenario.

Although there are significant gaps in the material data, the overall case conclusion is that the material flow assessment for oil and gas inputs provides an adequate basis to make preliminary inferences from the cross-case analysis.

\subsection{Pilot case study B: low rise apartment building}

Case B is a modified three storey low rise, medium density apartment building with lifts shown in figure 2. It is an economical rectangular steel reinforced concrete structure; with a ground level secure parking area and small offices, three levels of 13 typical 2-bedroom apartments and two 3-bedroom units. The 2bedroom apartments average $162 \mathrm{~m}^{2}$ GFA, comprising $130 \mathrm{~m}^{2}$ internal and $32 \mathrm{~m}^{2}$ balcony areas, as indicated in figure 4 . The results are presented in table 2 .

\subsubsection{Results summary of oil and gas related inputs}

Table 2: $\quad$ Summary of case B low rise apartment building analysis.

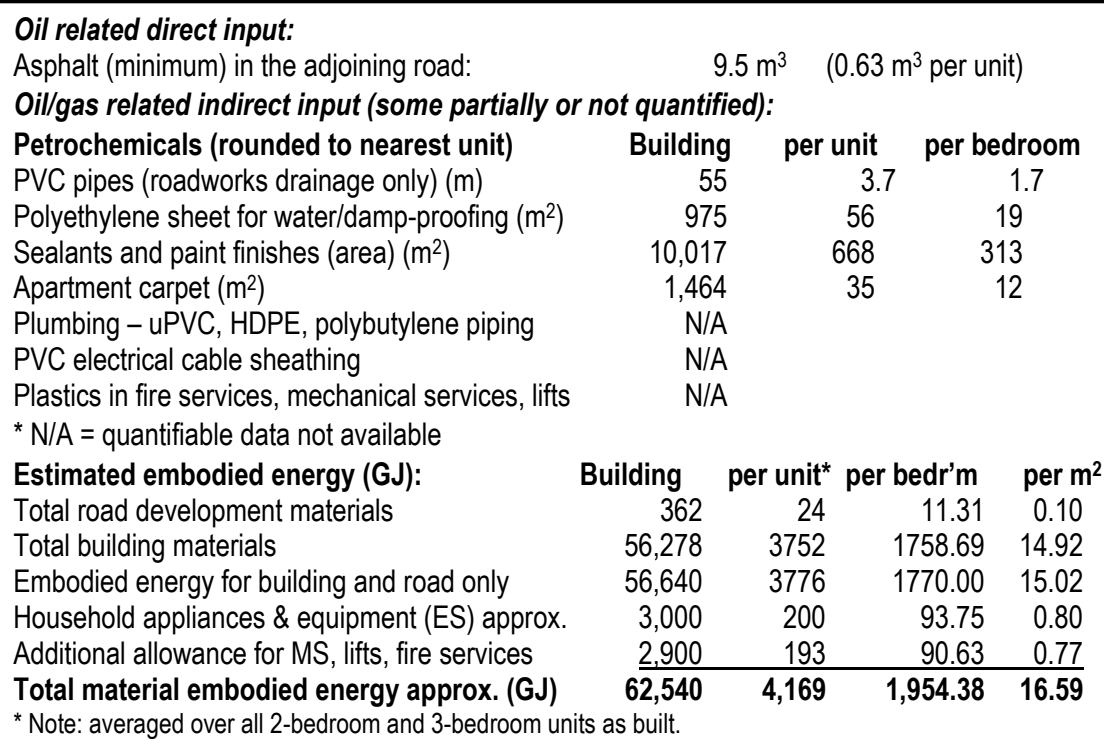




\subsubsection{Analysis of oil inputs findings}

This project uses an industry standard approach of a steel-reinforced concrete structure. A standard allowance is made for electrical, lifts and fire services per unit, for all the apartment buildings. An allowance for household appliances and equipment fitout is based on the case A study for consistency. On the basis of the modified building, the embodied energy of an average $162.3 \mathrm{~m}^{2}$ 2-bedroom apartment plus $75.4 \mathrm{~m}^{2}$ as a typical share of common areas (foyers, ground floor areas and parking) to total $237.7 \mathrm{~m}^{2}$ is 3,943 GJ. Major structural components in the substructure, columns, stairs, upper floors, (mainly) concrete external walls and roof account for $31,560 \mathrm{GJ}(50.4 \%)$ of the total embedded energy.

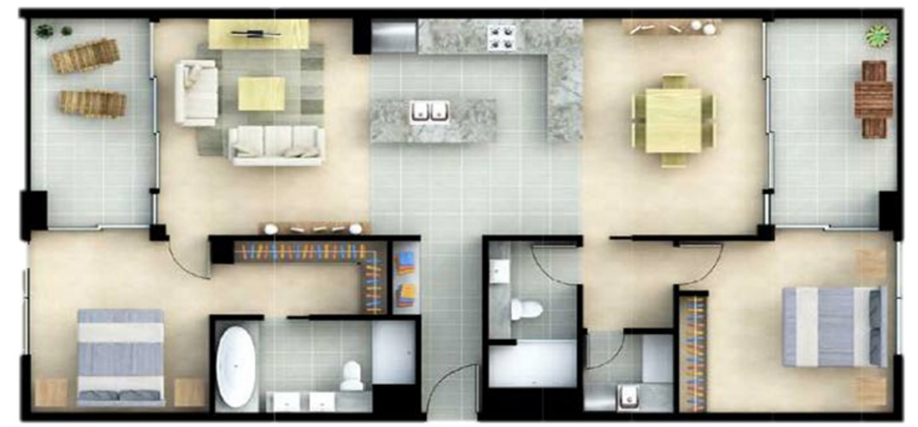

Figure 4: Typical two-bedroom apartment layout.

As in the other cases, the largest direct oil-related input is in the transport of materials and labour to the site and on-site diesel powered plant and equipment include dewatering pumps, concrete pumps and helicopter vibrators used on the concrete floors. This data is omitted due to lack of operating data provided. The direct oil input in the asphalt adjoining roads is less than $1 \mathrm{~m}^{3}$ per unit. Indirect oil and gas inputs are mainly petrochemicals. Using MFA analysis, the embodied energy components from diesel and gas for the steel and concrete materials and transport of bulk concrete, sand and gravel to the site total about 2353 GJ. If the energy intensity data indexes are correct, this represents only about $7.5 \%$ of the total structural embodied energy.

\subsection{Pilot case study $C$ : medium rise apartments}

Case $\mathrm{C}$ is a six-storey apartment building shown in figure 2 as a medium rise/high density development. The building is an elongated rectangular shaped steel reinforced concrete structure with a single underground basement, and a sheet steel roof. The 42 apartments have non-load bearing internal and external walls, except for the inter-unit separating walls and lift-stair well cores. The apartments are arranged in four sections, each with a separate street access and a small foyer. Each section has a single lift and stair access from the basement to higher floors. A typical floor has eight apartments, as indicated in figure 5. The average 3bedroom unit gross floor area is $183 \mathrm{~m}^{2}$, comprising $151 \mathrm{~m}^{2}$ internal and $32 \mathrm{~m}^{2}$ 
balcony areas, which is selected for the basis for comparison. The building is modified for the analysis by replacing the top penthouse level with a duplicated typical level, as a data set of 45 units in six levels plus the basement.

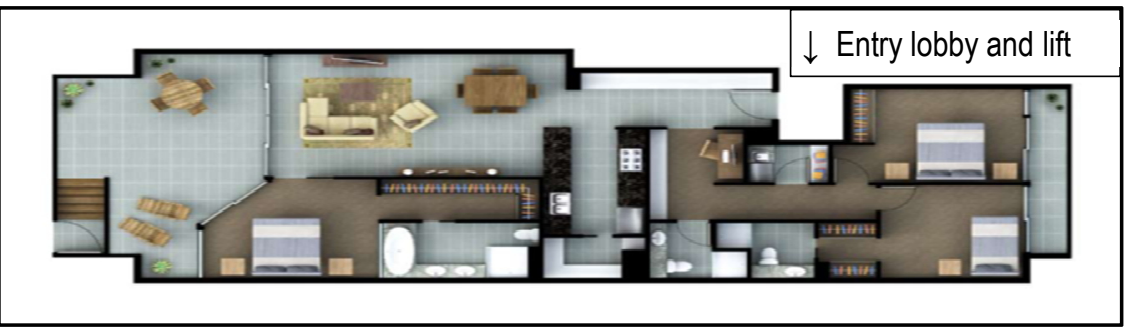

Figure 5: Typical three-bedroom comparison apartment.

\subsubsection{Results summary of oil and gas related inputs}

A summary of results for the as-constructed building is presented in table 3 .

Table 3: $\quad$ Summary of case C six storey apartment building analysis.

\begin{tabular}{|c|c|c|c|c|}
\hline \multicolumn{5}{|l|}{ Oil related direct input: } \\
\hline Asphalt (minimum) in the adjoining road: $28.5 \mathrm{~m} 3$ & \multicolumn{4}{|c|}{ (0.7 m3 per unit) } \\
\hline \multicolumn{5}{|c|}{ Oil/gas related indirect input (some partially or not quantified): } \\
\hline $\begin{array}{l}\text { Petrochemicals (rounded to nearest unit) } \\
\text { PVC pipes (roadworks only) }(\mathrm{m}) \\
\text { Polyethylene sheet for water/damp-proofing }\left(\mathrm{m}^{2}\right) \\
\text { Sealants and paint finishes (area) }\left(\mathrm{m}^{2}\right) \\
\text { Apartment carpet }\left(\mathrm{m}^{2}\right) \\
\\
\text { Plumbing - uPVC, HDPE, polybutylene piping } \\
\text { PVC electrical cable sheathing } \\
\text { Plastics in fire services, mechanical services, lifts } \\
\text { Kitchen and bathroom cabinets, robe shelving }\end{array}$ & $\begin{array}{r}12 \\
\mathrm{~N} / \mathrm{A} \\
\mathrm{N} / \mathrm{A} \\
\mathrm{N} / \mathrm{A} \\
\text { (Items) }\end{array}$ & $\begin{array}{r}8 \\
1,46\end{array}$ & Per bedr & $\begin{array}{l}\text { room } \\
2 \\
9 \\
4 \\
35\end{array}$ \\
\hline${ }^{*} \mathrm{~N} / \mathrm{A}=$ quantifiable data not available & & & & \\
\hline $\begin{array}{l}\text { Estimated embodied energy (GJ): } \\
\text { Total road development materials } \\
\text { Total building materials } \\
\text { Embodied energy for building and road only } \\
\text { ES Household appliances \& equipment approx. } \\
\text { Additional allowance for MS, lifts, fire services }\end{array}$ & $\begin{array}{r}\text { Building } \\
1,086 \\
139,762 \\
140,848 \\
8,400 \\
\underline{5,002} \\
\end{array}$ & $\begin{array}{c}\text { per unit* } \\
26 \\
3327.7 \\
3,353.7 \\
200 \\
119 \\
\end{array}$ & $\begin{array}{c}\text { per bedr'm } \\
9 \\
1,127.0 \\
1,136.0 \\
67.7 \\
40.3 \\
\end{array}$ & $\begin{array}{l}\text { per } \mathrm{m}^{2} \\
0.10 \\
12.91 \\
13.01 \\
0.78 \\
0.46 \\
\end{array}$ \\
\hline $\begin{array}{l}\text { Total material embodied energy approx. (GJ) } \\
* \text { Note: averaged over all units as built. }\end{array}$ & 154,250 & $3,672.7$ & $1,244.0$ & 14.25 \\
\hline
\end{tabular}




\subsubsection{Analysis of oil inputs findings}

Table 3 shows the approximate conservative embodied energy of building is $154,250 \mathrm{GJ}$ at $14.25 \mathrm{GJ} / \mathrm{m}^{2} \mathrm{GFA}$. On this basis the embodied energy of a typical $183.5 \mathrm{~m}^{2} 3$-bedroom/2-bathroom apartment plus about $63.5 \mathrm{~m}^{2}$ as a typical share of common areas (foyers, pool area, function room and basement) to total $247 \mathrm{~m}^{2}$ is 3,520 GJ. However, a sensitivity test of the modified building proposes a more representative example. The adjusted embodied energy for a 3-bedroom unit is $3,480 \mathrm{GJ}$ at $14.09 \mathrm{GJ} / \mathrm{m}^{2} \mathrm{GFA}$. This value is used for the cross-case comparison unit. Increasing the density of apartments reduces the embodied energy per dwelling by making more efficient use of the common areas and basement parking. This would be a preferred result, but is dependent upon a market willing to pay a premium for smaller three bedroom units rather than the usual penthouses at the highest level of the building, where most profit is made.

Using MFA analysis, the embodied energy components from diesel and gas for the steel and concrete materials and transport of bulk concrete, sand and gravel to the site total 5868.36 GJ. If the energy intensity data indexes are correct, this represents about $6.1 \%$ of the total structural embodied energy.

\subsection{Pilot case study D - high rise apartment tower}

Case D is an apartment tower shown in figure 2, representative of recent high rise/high density residential developments in the city. It occupies a site of $2673 \mathrm{~m}^{2}$ and the as-constructed 32 storey configuration has 170 dwelling units. This is a density of 636 dwellings (or 853 actual bedrooms) per net hectare. The total indoor area for the apartments and common areas is $21,327 \mathrm{~m}^{2}$, excluding the 3-level basements-equivalent to some 57 case A 4-bedroom houses. The form of construction is a steel reinforced concrete structure with a three underground basement levels, and sheet steel roof, served by three lifts and scissor fire stairs. The building has been modified to improve the analysis, by excising a lower amenities floor and converting the penthouse level to a typical level with six apartments, in a similar approach to the six storey case; making 172 total units.

Figure 6 shows the apartments on the larger $710 \mathrm{~m}^{2}$ typical modified levels 4 30 are arranged as six per floor in two mirrored sections around the core, comprising two 1-bedroom, two 1-bedroom plus study alcove, and two 2-bedroom apartments. The preferred 'typical' apartment is a 2-bedroom type of a similar area to the other cases, but which only comprise one third of all the apartments. In reality the mixed diversity of unit sizes in the tower case is more typical of this high density building type. The typical 2-bedroom end units are used for comparison purposes to assess embodied energy and oil/gas inputs in the range of building types. The gross floor area is $186.4 \mathrm{~m}^{2}-112 \mathrm{~m}^{2}$ internal and $11.8 \mathrm{~m}^{2}$ balcony areas, plus $62.6 \mathrm{~m}^{2}$ share of common areas and basements.

\subsubsection{Results summary of oil and gas related inputs}

Table 4 summary of oil and gas related inputs shows the conservative estimated embodied energy of building and adjoining road (half width) is 466,961 GJ and 16.50 GJ per $\mathrm{m}^{2}$. The unmodified average unit embodied energy is 2715 GJ. 
Modification of the building increases the average embodied energy of the comparison 2-bedroom unit to a higher value of $3075 \mathrm{GJ}$ at $16.50 \mathrm{GJ}$ per $\mathrm{m}^{2}$.

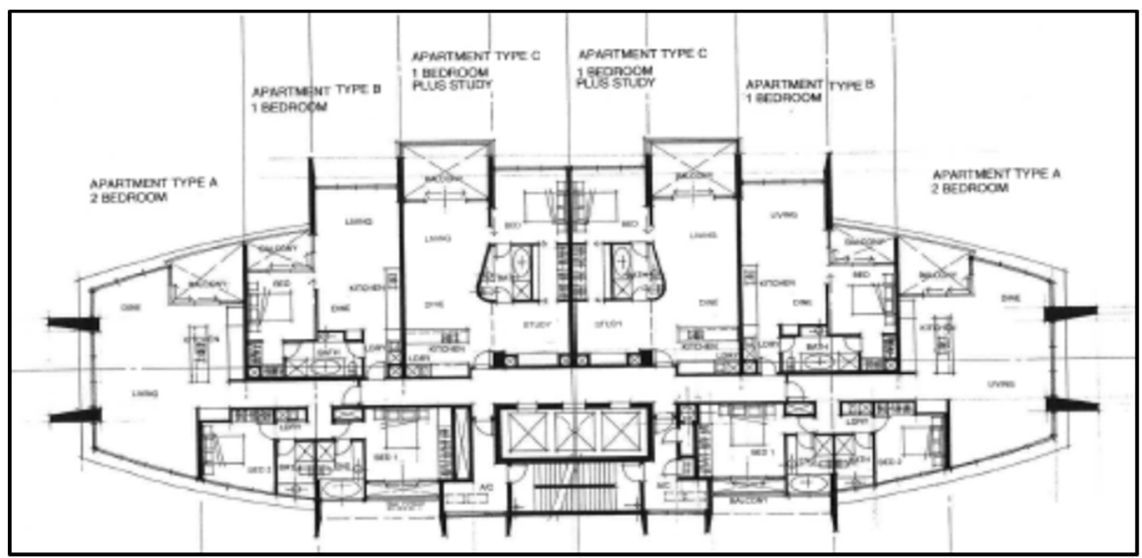

Figure 6: Typical high rise tower floor plan with six mirrored units.

Table 4: Summary of case D 30 storey apartment tower analysis.

\begin{tabular}{|c|c|c|c|c|}
\hline \multirow{2}{*}{\multicolumn{5}{|c|}{ Oil related direct input: }} \\
\hline & & & & \\
\hline \multicolumn{5}{|c|}{ Oil/gas related indirect input (some partially or not quantified): } \\
\hline $\begin{array}{l}\text { Petrochemicals: } \\
\text { PVC pipes (roadworks only) (from Case B) (m) } \\
\text { Polyethylene sheet for water/damp-proofing }\left(\mathrm{m}^{2}\right) \\
\text { Sealants and paint finishes (area) }\left(\mathrm{m}^{2}\right) \\
\text { Apartment carpet (includes corridors carpet) }\left(\mathrm{m}^{2}\right) \\
\text { Plumbing - uPVC, HDPE, polybutylene piping } \\
\text { PVC electrical cable sheathing } \\
\text { Plastics in Fire services, mechanical services, lifts } \\
{ }^{*} \text { N/A = quantifiable data not available }\end{array}$ & \multicolumn{2}{|c|}{$\begin{array}{c}\text { Building } \\
55 \\
9,300 \\
80,336 \\
13,719 \\
\mathrm{~N} / \mathrm{A}^{*} \\
\mathrm{~N} / \mathrm{A}^{*} \\
\mathrm{~N} / \mathrm{A}^{*}\end{array}$} & $\begin{array}{c}\text { er unit Per bed } \\
0.3 \\
54.1 \\
467.1 \\
79.2\end{array}$ & $\begin{array}{l}\text { droom } \\
0.2 \\
40.8 \\
352.4 \\
-\end{array}$ \\
\hline $\begin{array}{l}\text { Estimated embodied energy (GJ): } \\
\text { Total road development materials (Case B) } \\
\text { Total building materials } \\
\text { Embodied energy for building and road only } \\
\text { Additional allowance for lifts and fire services }\end{array}$ & $\begin{array}{r}\text { Building } \\
362 \\
446,599 \\
446,961 \\
20,000 \\
\end{array}$ & $\begin{array}{r}\text { per unit } \\
2.10 \\
2,596.51 \\
2,598.61 \\
116.28 \\
\end{array}$ & $\begin{array}{c}\text { t* }^{\star} \text { per bedr'm } \\
1.59 \\
1,958.77 \\
1960.36 \\
87.72 \\
\end{array}$ & $\begin{array}{c}\text { per } \mathrm{m}^{2} \\
0.01 \\
15.78 \\
15.79 \\
0.71 \\
\end{array}$ \\
\hline $\begin{array}{l}\text { Total material embodied energy approx. } \\
\text { *Note: averaged over all units as built. }\end{array}$ & 466,961 & $2,714.9$ & $2,048.1$ & 16.50 \\
\hline
\end{tabular}




\subsubsection{Analysis of oil inputs findings}

This project uses an industry standard approach for high rise construction of a steel reinforced concrete structure and a combination of poured concrete, limited concrete block and mainly window walls. The major structural components in the substructure, columns, stairs, upper floors, (mainly) concrete walls and roof account for 333,492 GJ $(71.4 \%$ ) of the 466,961 GJ total embodied energy. This proportion is very close to the six storey value (72.5\%). Using MFA analysis, the embodied energy components from diesel and gas for steel and bulk concrete materials, concrete block walls, plus an additional allowance for transport of bulk concrete, sand and gravel to the site total 16,424.6 GJ. This calculation excludes the oil and gas inputs into the external window walls and sliding doors $\left(9396 \mathrm{~m}^{2}\right)$ and the non-load bearing metal frame internal partition walls $\left(8694 \mathrm{~m}^{2}\right)$. The oil and gas embodied energy is $648 \mathrm{GJ}$ for the glass and $56 \mathrm{GJ}$ for the steel. These additions increase the oil and gas embodied energy to about 17,130 GJ, which is a minimum of $5.1 \%$ of the total structure.

This type of high rise building relies on more centralised and efficient organisation of the supply chain than detached housing and effectively constructs 170 small dwellings in a single large house lot footprint. The largest direct oilrelated input is in the transport of materials and labour to the site. The central city location exacerbates the transport problems in at least two ways-by a longer supply chain and through a more congested part of the road system. The tentative conclusion is that a tall building may have less embodied energy, providing the market is willing to pay a premium for small units in a central city location.

\section{Cross-case comparison}

The aim in comparing the case study data is to determine the relative impact of oil inputs on each dwelling category. The initial comparison is between the reference house and the apartment cases, leading to analysis of the energy intensity indices. It also considers the influence of occupancy rates on the calculated results that may modify the initial conclusions. The analysis is shown graphically in figures 7 and 8 , based on the results summarised in table 5 .

Two occupancy rates are used: a 'typical' value and a census based statistical value. The typical value is suggested as the 'design' occupancy for a dwelling in each case based on the likely ultimate whole number, or averaged for the high rise apartments at 1.5 The second occupancy rate is based on census statistical values provided by the Gold Coast City Council [6] as being average for each type of locality, ranging from central to inner urban and outer suburban areas. 


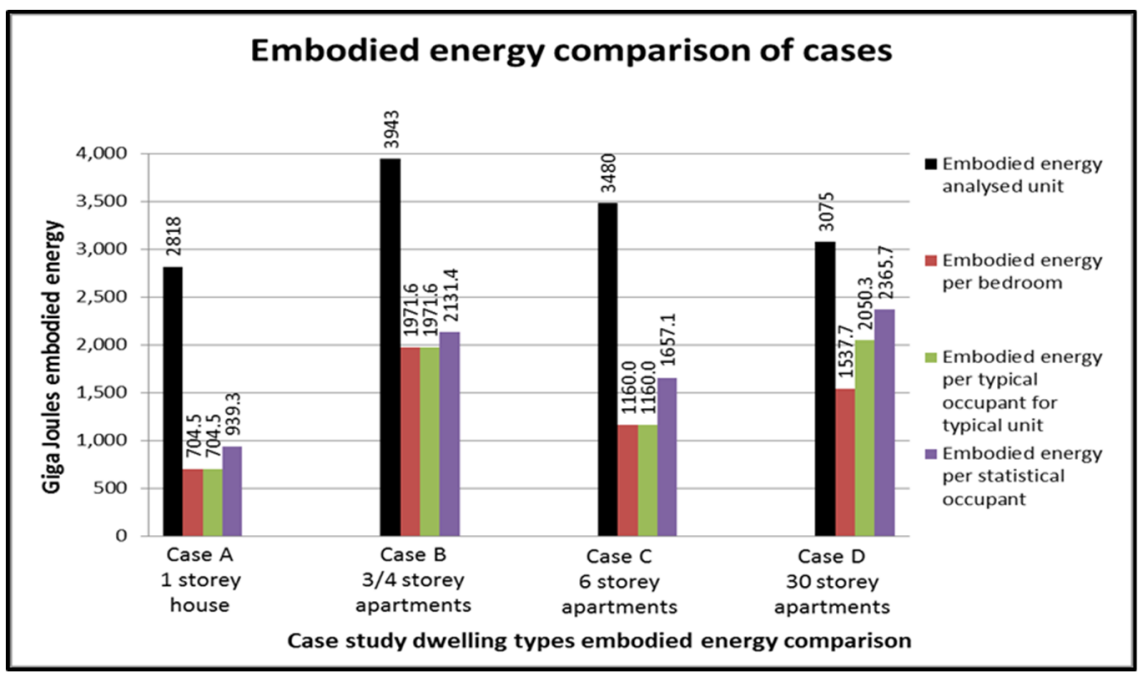

Figure 7: Embodied energy results for cross-case comparison.

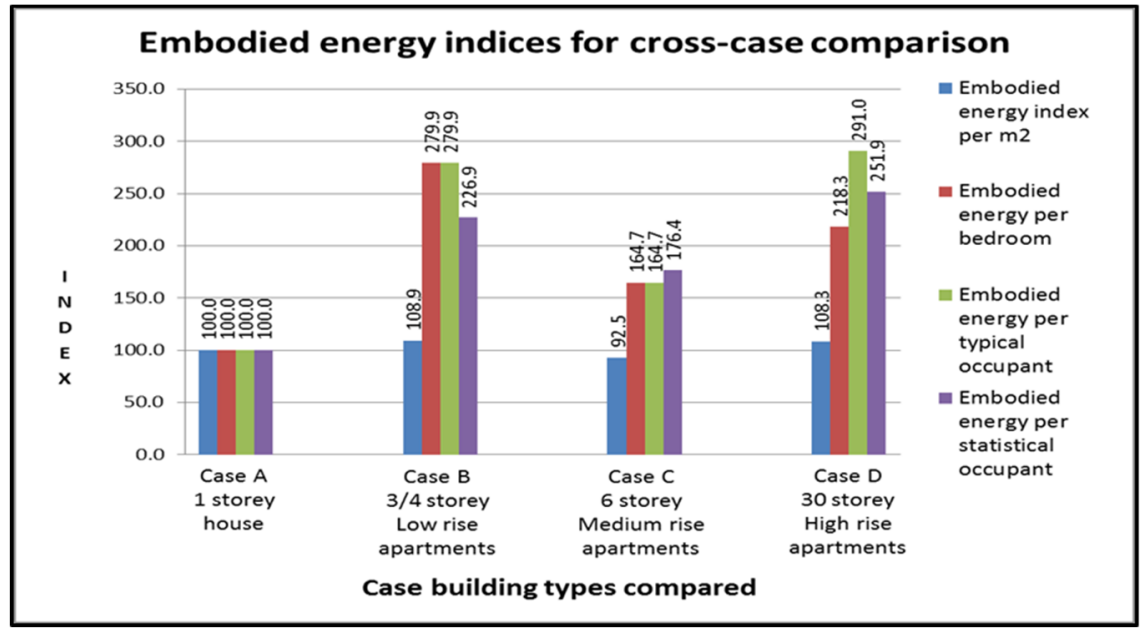

Figure 8: Embodied energy indices for cross-case comparison. 
Table 5: Case study types: comparison of recorded embodied energy.

\begin{tabular}{|c|c|c|c|c|c|c|c|}
\hline \multirow[t]{2}{*}{ Characteristic } & \multirow[t]{2}{*}{$\begin{array}{c}\text { Case A: } \\
\text { detached } \\
\text { house } \\
\end{array}$} & \multicolumn{2}{|c|}{$\begin{array}{c}\text { Case } B: \\
3 / 4 \text { storey } \\
\text { low rise units }\end{array}$} & \multicolumn{2}{|c|}{$\begin{array}{c}\text { Case C: } \\
6 \text { storey } \\
\text { medium rise units }\end{array}$} & \multicolumn{2}{|c|}{$\begin{array}{c}\text { Case D: } \\
30 \text { storey } \\
\text { high rise units }\end{array}$} \\
\hline & & Description & data & Description & data & Description & data \\
\hline No of storeys as analysed & 1 & & 3 & & 6 & & 30 \\
\hline Parking arrangements & $\begin{array}{l}\text { Internal } \\
\text { double } \\
\text { garage }\end{array}$ & \begin{tabular}{|c|} 
Secure \\
internal \\
ground level \\
parking
\end{tabular} & & $\begin{array}{c}1 \\
\text { basement } \\
\text { level }\end{array}$ & & $\begin{array}{c}3 \\
\text { basement } \\
\text { levels }\end{array}$ & \\
\hline Total dwelling units as analysed & 1 & & 15 & & 45 & & 172 \\
\hline $\begin{array}{l}\text { Total number of equivalent } \\
\text { bedrooms based on typical unit }\end{array}$ & 4 & 2-bed unit & 13 & $\begin{array}{c}37 \text { typical } \\
\text { 3-bed units }\end{array}$ & 111 & \begin{tabular}{|c|}
2 -bedroom \\
56 units
\end{tabular} & 112 \\
\hline $\begin{array}{l}\text { Total number of equivalent } \\
\text { bedrooms secondary unit }\end{array}$ & & 3-bed & 2 & $\begin{array}{c}7 \\
\text { 2-bed units }\end{array}$ & 14 & \begin{tabular}{|c|}
$1+1$ \\
bedroom \\
58 units
\end{tabular} & 58 \\
\hline $\begin{array}{l}\text { Total number of equivalent } \\
\text { bedrooms other units }\end{array}$ & & & & \begin{tabular}{|c|} 
penthouse \\
3-bed unit \\
\end{tabular} & 3 & $\begin{array}{c}\text { 1-bedroom } \\
58 \text { units } \\
\end{array}$ & 58 \\
\hline Total bedrooms & 4 & & 32 & & 128 & & 228 \\
\hline Total building area $\mathrm{m} 2 \mathrm{GFA}$ & 185.0 & & $3,770.0$ & & $11,016.0$ & & $28,302.0$ \\
\hline \multicolumn{8}{|l|}{ Comparison unit: } \\
\hline Average internal area m2 GFA & 132.0 & & 130.0 & & 147.0 & 2-bed unit & 112.0 \\
\hline Average external area $\mathrm{m} 2$ & 17.0 & & 32.3 & & 36.0 & 2-bed unit & 11.8 \\
\hline Average total unit area $\mathrm{m} 2$ & 149.0 & & 162.3 & & 183.5 & 2-bed unit & 123.8 \\
\hline $\begin{array}{l}\text { Average common/parking area } \\
\text { allocation } \mathrm{m} 2\end{array}$ & 36.0 & & 75.4 & & 63.5 & & 62.6 \\
\hline Average total area $\mathrm{m}^{2}$ & 185.0 & & 237.7 & & 247.0 & & 186.4 \\
\hline Embodied energy for building & 2,818 & & 62,540 & & 155,204 & & 466,961 \\
\hline $\begin{array}{l}\text { Total building } \\
\text { Embodied energy per } \mathrm{m}^{2}\end{array}$ & 15.23 & & 16.59 & & 14.09 & & 16.50 \\
\hline Embodied energy analysed unit & 2,818 & & 3,943 & & 3,480 & & 3,075 \\
\hline Embodied energy per bedroom & 704.5 & & $1,971.6$ & & $1,160.0$ & & $1,537.7$ \\
\hline Typical occupancy for type & \begin{tabular}{l|l}
4 & \\
\end{tabular} & & 2 & & \begin{tabular}{l|l}
3.0 \\
\end{tabular} & & 1.5 \\
\hline $\begin{array}{l}\text { Embodied energy per typical } \\
\text { occupant for typical unit }\end{array}$ & 704.5 & & $1,971.6$ & & $1,160.0$ & & $2,050.3$ \\
\hline Statistical occupancy in area & 3.0 & & 1.85 & & \begin{tabular}{l|l}
2.1 \\
\end{tabular} & & 1.3 \\
\hline $\begin{array}{l}\text { Embodied energy per statistical } \\
\text { occupant }\end{array}$ & 939.33 & & $2,131.4$ & & $1,657.1$ & & 2,365.7 \\
\hline $\begin{array}{l}\text { EMBODIED ENERGY INDEX - } \\
\text { based on } E E / \mathrm{m}^{2} \text { total area }\end{array}$ & 100.0 & & 108.9 & & 92.5 & & 108.3 \\
\hline $\begin{array}{l}\text { EMBODIED ENERGY INDEX - } \\
\text { per equivalent bedroom }\end{array}$ & 100.0 & & 279.9 & & 164.7 & & 218.3 \\
\hline $\begin{array}{l}\text { EMBODIED ENERGY INDEX - } \\
\text { per typical occupant }\end{array}$ & 100.0 & & 279.9 & & 164.7 & & 291.0 \\
\hline $\begin{array}{l}\text { EMBODIED ENERGY INDEX - } \\
\text { per statistical occupant }\end{array}$ & 100.0 & & 226.9 & & 176.4 & & 251.9 \\
\hline
\end{tabular}

\section{Discussion}

The premise of the case studies is that some residential building types above about three storeys are more reliant on technology and possibly relatively more vulnerable in an oil constrained scenario. The cross-case analysis shows the 
relative embodied energy per dwelling unit, per bedroom and per occupant for the comparison house and units. The six-storey apartment building performs better than low or high rise buildings on all these criteria and in the embodied energy per $\mathrm{m}^{2}$ GFA indexed against the house. The house has least embodied energy on the other criteria because it has more bedrooms and a modest total area. However, the six storey building is the next lowest be a wide margin. The graph in figure 8 comparing embodied energy intensity indices conveys seemingly clear relationships between building types, but actually disguise complex comparisons. The somewhat surprising tentative result is that the oil/ gas proportion of total structural embodied energy is $21 \%$ of the house, but only an average $6 \%$ of the apartment buildings. On the basis of these pilot cases, the building construction is not as significant as the type-form, height and density.

Transport of materials and labour is the largest direct oil-related input in all the cases of the study, based on current transport fuels. All the road transport currently relies on diesel, petrol or LPG powered vehicles, and hence on the oil economy. The deceptively small recorded transport embodied energy in each case is therefore not the whole story in examining the possible impacts in an oil constrained scenario. Non-energy factors are important, including the acceptance of apartment living in preference to the traditional suburban detached house. The six storey 3-bedroom apartments are in fact larger than the 4-bedroom house and would provide suitable family accommodation for two adults and two children.

These studies are used in further $\mathrm{PhD}$ research by the author to inform consideration of which urban forms should be promoted in spatial planning, and will reinforce outcomes of other studies - e.g. urban transport and operational energy - to manage city growth and urban form in an oil constrained future.

\section{References}

[1] United Nations Human Settlements Programme 2009, Planning sustainable cities: global report on human settlements, Earthscan, London, p.5, 2009.

[2] International Energy Agency, World energy outlook 2013: Executive Summary, International Energy Agency and OECD, Paris, pp. 4-5, 2013.

[3] Brewster, R.J., 'Significance of global oil depletion to urban residential development', in CA Brebbia (ed.), Sustainability today, WIT Press, Southampton, pp. 151-163, 2012.

[4] Duany, A., Speck, J. \& Lydon, M., The smart growth manual, McGraw Hill, New York, 2010.

[5] Crawford, R.H., Life cycle assessment in the built environment, Spon Press, Abingdon, Oxon, UK, pp. 90-94, 2011.

[6] Gold Coast City Council, Gold Coast community profile-social atlas, viewed 15 August 2013, www.profile.id.com.au/ gold-coast, 2013. 